Int. J. Electrochem. Sci., 11 (2016) $4729-4742$

\title{
Fabrication and Applications of Potentiometric Sensors Based on $p$-tert-butylthiacalix[4]arene Comprising Two Triazole Rings Ionophore for Silver Ion Detection
}

\author{
Omran A. Omran ${ }^{1,4, *}$ Fadl A. Elgendy ${ }^{2}$ and Ayman Nafady ${ }^{3,4 . *}$ \\ ${ }^{1}$ College of Science in Zulfi, Majmaah University, Zulfi 11932, Saudi Arabia, \\ ${ }^{2}$ Chemistry Department, College of Science, Qassim University, Saudi Arabia \\ ${ }^{3}$ Department of Chemistry, College of Science, King Saud University, Riyadh, Saudi Arabia \\ ${ }^{4}$ Chemistry Department, Faculty of Science, Sohag University, Sohag 82524, Egypt. \\ *E-mail: anafady@ksu.edu.sa and o.omran@mu.edu.sa
}

doi: $10.20964 / 2016.06 .35$

Received: 13 February 2016 / Accepted: 8 March 2016 / Published: 4 May 2016

This work describes the fabrication and applications of potentiometric silver-selective sensors, based on the use of a newly synthesized p-tert-butylthiacalix[4]arene comprising two triazole rings, as a novel neutral ionophore in plasticized poly(vinyl chloride) (PVC) membranes. The effect of lipophilic anionic additives on the voltammetric responses of the sensors was investigated in details. The constructed sensors exhibited a Nernstian behavior with $53 \pm 0.9 \mathrm{mV}$ per decade change in $\mathrm{Ag}^{+}$ activity over the range from $7.0 \times 10^{-6}$ to $8.0 \times 10^{-3}$, with a repetitive detection limit of $0.421 \mu \mathrm{g} \mathrm{mL}^{-1}$. Moreover, the effect of lipophilic salts, plasticizers and various interfering ions were probed. Importantly, validation of the method is achieved in terms of good performance characteristics, including good selectivity for $\mathrm{Ag}^{+}$over alkali, alkaline earth and transition metal ions (e.g. $\mathrm{Na}^{+}, \mathrm{K}^{+}$, $\mathrm{Pb}^{2+}, \mathrm{Mg}^{2+}, \mathrm{Co}^{2+} \mathrm{Ni}^{2+}$, and $\left.\mathrm{Cu}^{2+}\right)$ together with long life span. Other important characteristics such as low detection limit, acceptable accuracy and precision, long term stability, reproducibility were also demonstrated. On the application side, the sensors were utilized for facile potentiometric measurements of iodide ions $\left(\mathrm{I}^{-}\right)$over the concentration range of 0.749 to $856 \mu \mathrm{g} \mathrm{mL}^{-1}$ and also employed for probing sequential titration of some importantly relevant anions (e.g. $\mathrm{Cl}^{-}, \mathrm{Br}^{-}, \mathrm{I}^{-}, \mathrm{SCN}^{-}$ and $\mathrm{N}^{-3}$ ). Significantly, sequential binding of these anions with $\mathrm{Ag}^{+}$cations produces sharp stepwise titration curves with consecutive end point breaks at the equivalent points.

Keywords: Thiacalix[4]arenes; silver-ion selective electrode ; Potentiometry. 
(C) 2016 The Authors. Published by ESG (www.electrochemsci.org). This article is an open access article distributed under the terms and conditions of the Creative Commons Attribution license (http://creativecommons.org/licenses/by/4.0/). 